\section{PRÁTICAS DE EDUCAÇÃO AMBIENTAL NO ENSINO INFANTIL: O TRABALHO DA ESCOLA Prof. á ÁUREA MELO ZAMOR EM ARACAJU-SE}

\author{
Verusia Maruiza de Souza Macedo Firmino \\ Alana Danielly Vasconcelos
}

\section{Resumo}

A Educação infantil tem um papel importante na preservação e conservação do meio ambiente, pois, se desde os primeiros anos de vida, a criança aprender a ter uma consciência ambiental, futuramente estas poderão se tornar agentes participativos do processo de ensino aprendizagem. O objetivo desse trabalho foi analisar como vem sendo trabalhado a educação ambiental no ensino infantil, para que as crianças adquiram conhecimentos, desenvolvam habilidades, e se tornem conscientes e sensíveis no que se refere ao meio ambiente. A atividade realizada com os alunos foi um jogo educativo da memória, sobre as espécies de plantas existentes no âmbito escolar. O instrumento de coleta foi um questionário, que buscou responder os objetivos estabelecidos na pesquisa, através da análise dele e da observação das aulas, foi possível verificar que existe um trabalho de Educação Ambiental na escola e que os alunos aprendem sobre meio ambiente. A educação é uma ferramenta importante na sensibilização ambiental, visto que quanto mais cedo se começa esse trabalho, mais as crianças aprendem e levam esse conhecimento para toda a vida.

Palavras-chave: Educação Ambiental; Ensino Infantil; Aracaju, práticas em educação ambiental.

\section{ENVIRONMENTAL EDUCATION PRAC- TICES IN CHILDREN'S EDUCATION: THE WORK OF SCHOOL Prof. á ÁUREA MELO ZAMOR IN ARACAJU-SE}

\begin{abstract}
The education of children has an important role in the preservation and conservation of the environment, since if, from the earliest years of life, the child learns to have an environmental conscience, in the future these can become participatory agents of the teaching learning process. The objective of this study was to analyze how environmental education has been developed in children's education, so that children acquire knowledge, develop skills, and become aware and sensitive regarding the environment. The activity performed with the students was an educational game of memory about the species of plants existing in the school environment. The collection instrument was a questionnaire, which sought to answer the objectives established in the research, through its analysis and observation of the classes, it was possible to verify that there is an Environmental Education work in the school and that the students learn about the environment. Education is an important tool in environmental awareness, since the earlier this work begins, the more children learn and take that knowledge for a lifetime.
\end{abstract}

Keywords: Environmental Education; Teaching infant; Aracaju, practices in environmental education. 


\section{Introdução}

A educação ambiental quando inserida no contexto escolar, principalmente na educação infantil, tem um papel importante na preservação e conservação do meio ambiente, pois, se desde os primeiros anos de vida, a criança aprender a ter uma consciência ambiental, futuramente estas poderão se tornar agentes participativos do processo de ensino aprendizagem, em prol do meio ambiente.

De acordo com Silva, (2016):

A educação ambiental inserida nas práticas escolares pode significar a inserção da escola e dos saberes, que se processam em seu interior em um movimento de análise e reflexão profunda do sentido de estar no mundo, vendo-o como potência e possibilidade.

O educador pode auxiliar na conscientização ambiental, pois, quando inserida nas práticas escolares, a educação ambiental faz com que os educandos reflitam desde cedo que é preciso cuidar, preservar e conservar o meio ambiente.

As hipóteses levantadas nessa pesquisa foram: existe uma falta de conhecimento dos alunos em relação aos problemas ambientais; não são elaboradas práticas eficientes para o ensino infantil em educação ambiental.

O presente trabalho enfatiza o meio ambiente no Ensino Infantil, tendo como problemática: as práticas do ensino infantil em educação ambiental têm proporcionado conhecimentos e aptidões capazes de mudar atitudes nos alunos e professores, no âmbito da Escola Prof ${ }^{a}$ Áurea Melo Zamor em Aracaju-SE?

Assim, o objetivo geral foi analisar como vem sendo trabalhada a educação ambiental no ensino infantil, para que as crianças adquiram conhecimentos desenvolvendo habilidades e se tornem conscientes e sensíveis no que se refere ao meio ambiente.

Essa pesquisa teve por objetivos específicos: identificar as práticas que são utilizadas no ensino infantil em educação ambiental; observar como as práticas são desenvolvidas na educação ambiental do ensino infantil; determinar como a professora desperta o interesse dos alunos para as práticas de educação ambiental no nível infantil.

De acordo com Oliveira e Toniosso, (2016):

É de suma importância que a sociedade possua conhecimento sobre a realidade ambiental, para que ocorra o desenvolvimento de uma consciência que favoreça a elaboração de abordagens curriculares relacionadas ao meio ambiente.

Torna - se necessária à realização dessa pesquisa, para verificar o que os alunos aprendem, no ensino infantil, sobre meio ambiente, através da prática da educação ambiental.

A educação infantil, por ser o começo da vida escolar, é onde deve ser despertada na criança a consciência da conservação e preservação ambiental para que, os alunos, adquirindo esse conhecimento, mobilizem o local em que estão inseridos, no cuidado com o meio ambiente.

\section{A educação ambiental no ensino infantil}

A instituição escolar desempenha um papel significativo na formação do ser humano, sendo determinante no processo de ensino aprendizagem. $\mathrm{Na}$ educação infantil faz-se necessário que seja enfatizada a sensibilização das crianças para com a natureza, destacando a diversidade dessa relação.

De acordo com Hansen, (2017):

É fundamental envolver as crianças em abordagens sobre o meio ambiente, com criatividade e sensibilidade, para que se percebam como elemento importante de transformação onde cada um é responsável e pode fazer a sua parte para que possamos viver num mundo melhor, mais saudável.

É importante que os educandos tenham uma consciência ambiental de que os recursos naturais se esgotam e que o principal responsável pela degradação do meio ambiente é o homem. O papel da escola diante dessa realidade ambiental é fundamental, pois ela pode levar os discentes a refletirem sobre suas ações no meio ambiente, fazendo com que estes tenham uma mudança de postura e atitudes.

Segundo Moreira e Costa, (2017):

A educação ambiental no contexto da educação infantil deve buscar valores que conduzam a uma convivência harmoniosa com o ambiente e as demais espécies que habitam o planeta, auxiliando as crianças a analisar criticamente o princípio que tem levado à destruição 
inconsequente dos recursos naturais e de várias espécies.

O educador, ao longo da vida escolar, tem grande importância na formação de cidadãos críticos e conscientes, aptos na conservação e preservação do meio ambiente. Os conteúdos ambientais oferecidos aos educandos devem respeitar a sua realidade, para que as crianças possam aprender sobre as práticas ambientais do seu dia a dia.

\section{O uso de jogos didáticos no ensino infantil}

O jogo educativo é uma excelente ferramenta que pode ser utilizada pelo educador no processo de ensino aprendizagem de seus alunos. A utilização dessa metodologia possibilita aos estudantes aprender regras e conteúdos de forma natural, proporcionando também uma maior interação entre o educador e os discentes ajudando em seu desenvolvimento cognitivo, crítico e motor.

Segundo Costa Pinto, et al, (2016), "a exploração do aspecto lúdico, pode se tornar uma técnica facilitadora na elaboração de conceitos, no reforço de conteúdos, na sociabilidade entre os alunos, no desenvolvimento da criatividade."

Através do lúdico, os alunos podem manifestar sua criatividade, tornando-se participativos e desenvolvendo habilidades como coordenação, rapidez, concentração, para se comunicarem dentro do jogo.

De acordo com Silva, et al, (2016):

$\mathrm{O}$ jogo tem que ser desafiador para o aluno, para que não se torne uma atividade monótona e com isto perca seu atrativo pedagógico. Ao fazer com que o aluno participe do processo pedagógico, ele pode constantemente fazer alterações que o estimulem a continuar a usá-lo.

O jogo precisa ser interessante e desafiador para que os alunos se sintam motivados a participar. E necessário que o docente seja um mediador na hora do jogo, para que ocorra uma assimilação melhor do conteúdo abordado por parte dos alunos e que esta seja uma atividade dinâmica e prazerosa.

Conforme o autor supracitado:

A utilização de atividades práticas no ensino da educação ambiental como es- tratégia de ensino é uma excelente ferramenta que proporciona aos educandos a sensibilização e a vivência de maneira mais prazerosa, gerando aumento da participação e interesse dos mesmos a respeito dos assuntos abordados, pois promovem motivação e facilitam a construção do conhecimento no processo de ensino-aprendizagem (COUTO, et al, 2016).

Para Silva, et al, (2016):

Quando utilizado de maneira adequada, o lúdico proporciona ao aluno e ao professor o possível alcance de objetivos esperados de forma prazerosa. Obviamente não se pode negar a importância de atividades convencionais em nosso cotidiano.

É importante que os jogos educativos sejam utilizados como instrumento de apoio, relacionado à aprendizagem de um conteúdo abordado, aumentando, assim, a construção do conhecimento através do lúdico.

\section{Procedimentos metodológicos}

Para a realização dessa pesquisa foi necessário primeiramente que fosse feita uma revisão bibliográfica para se obter reflexões sobre a importância da educação ambiental no ensino infantil.

O presente trabalho foi realizado através de uma intervenção, na escola Prof. ${ }^{\mathrm{a}}$ Áurea Melo Zamor. O ambiente escolar é composto por 230 alunos e 12 docentes nos dois turnos da escola, manhã e tarde. De acordo com a direção escolar, dentre esses professores alguns se destacam mais no que se refere à prática em educação ambiental, tais como a professora que guia a turma do $3^{\circ} \mathrm{A}$ do ensino infantil, no turno da manhã, composta por 15 alunos e, por conta disso, a escolha dessa turma.

Foram observados três dias de aula na turma, com a finalidade de identificar quais as atividades eram desenvolvidas com as crianças no que se refere à educação ambiental e se os alunos possuem o hábito de conservar e preservar o meio ambiente em que estão inseridos.

O instrumento de coleta, para a identificação de como é trabalhada a temática de educação ambiental, foi um questionário com 10 questões, que buscaram responder os objetivos estabelecidos nesta pesquisa, aplicado à professora da turma $\mathrm{e}$ 
à coordenadora da escola, sendo um total de 12 professores que compõem o corpo docente escolar.

A atividade realizada com os alunos foi um jogo educativo da memória, que envolveu todo o ambiente escolar, sobre as espécies de plantas existentes na escola, trabalhado em sala de aula. A partir de fotos reais da própria escola, foi confeccionada uma gravura com o nome cientifico e outra gravura com o nome popular, das espécies vegetais existentes no âmbito escolar. Esse jogo foi plastificado e ficou com a professora da turma para que fosse trabalhado mais vezes em sala de aula com os alunos.

Para confeccionar o jogo foi necessário: cartolina, papel contact, cola, tesoura e as gravuras das plantas existentes na escola impressas coloridas.

Figura 1. Material utilizado para confeccionar o jogo da memória sobre as espécies de plantas existentes na escola.

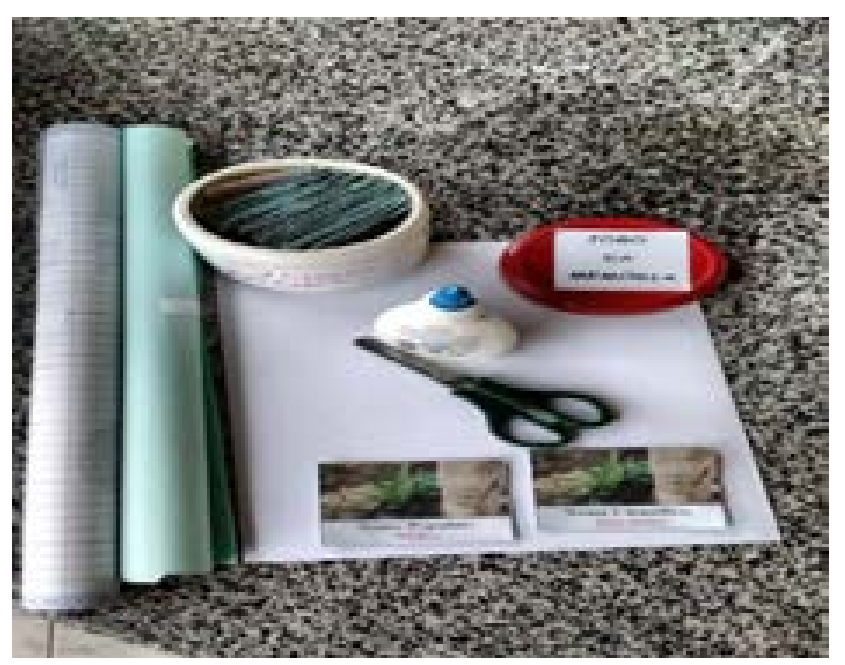

Fonte: (Arquivo pessoal; 2016).

Por fim, em uma roda de conversa com os alunos, foram passadas as orientações e regras do jogo da memória. Após a realização do jogo da memória das espécies de plantas, os alunos foram levados até essas espécies, a fim de identificá-las depois de observadas no jogo.

\section{Resultados e discussão}

Está comprovado cientificamente que é na primeira infância (até os 6 anos de idade) que a criança desenvolve grande parte do potencial mental que terá quando adulto. Sendo assim, essa fase constitui-se uma janela de oportunidades. (Lima, et al, 2017).
Priorizar a educação ambiental na infância é uma forma de educar as crianças, para um consumo consciente do meio ambiente. Através das observações foi possível verificar que são realizadas atividades em educação ambiental no âmbito escolar, levando em consideração que a escola é composta por 12 professores, pela equipe diretiva, técnicos da escola, cozinheiras, dentre outros funcionários, que participam frequentemente de atividades de proteção e conservação do meio ambiente.

Pode-se dizer que não há limites de idade para a Educação Ambiental, pois ela tem um caráter variável e dinâmico o qual procura adequar os conteúdos às faixas etárias (Aresi e Manica, 2018).

Com o estímulo da professora da turma, após a realização da alimentação, que ocorre na hora do recreio, por parte dos discentes, é realizada uma compostagem da sobra da merenda, evitando a poluição do ambiente escolar e fazendo com que a matéria orgânica seja utilizada de forma útil no solo da escola. Por ser uma escola arborizada e ocorrer plantação de milho e feijão, após a compostagem, os discentes regam as plantações existentes na escola.

A Educação Ambiental pode ser capaz de alterar a postura do cidadão face à realidade e os problemas socioambientais existentes. Esta questão vem a cada dia sendo aprofundada e causando reflexões e propostas a respeito desta temática, visando o bem-estar do ser humano e da natureza para as gerações atuais e futuras (Lopes, Rego e Rosário, 2018).

Foi observado que os alunos adquiriram o conhecimento de não colocar água demais nas plantas, tanto para não desperdiçar, como porque não são necessárias grandes quantidades de água nelas, pois a mesma em excesso gera a morte dos vegetais quando estes são pequenos.

$\mathrm{O}$ ato das crianças regarem as plantações e participarem da compostagem faz com que elas se tornem agentes participativos do processo de ensino aprendizagem. Aguar as plantas, escavar e enterrar os restos alimentares após a alimentação, esses são momentos, que os alunos gostam e participam ativamente.

Com a observação dessas atividades práticas, verificou-se que os discentes têm dificuldades em identificar as espécies de plantas existentes no âmbito escolar. As dificuldades podem surgir através de uma falta de atenção por parte dos alunos e também pela quantidade de espécies ve- 
getais existentes na escola, por serem crianças na faixa etária de três anos a identificação dessas espécies ocorre ao longo do tempo com a repetição do ensino.

Para que os alunos conseguissem identificar as espécies de plantas existentes na escola, foi realizada uma atividade prática. Em um primeiro momento na sala de aula, foi explicado aos alunos o que era o jogo da memória e qual a finalidade dele. Após a explicação, os discentes não estavam entendendo como jogar, então foi modificada a estratégia.

A princípio os educandos viravam uma carta e tentavam achar a outra imagem pela memória. $\mathrm{O}$ método inicial não estava surtindo efeito então para que ocorresse uma melhor observação por parte dos alunos, foi informado que virassem uma carta e procurassem a outra imagem igual, quando encontravam ficavam com a carta.

Quando foi encerrado o jogo, questionou-se aos educandos se gostaram dessa atividade e, após esse momento, os alunos foram levados a cada espécie de planta existente no jogo, para que as identificassem.

A cada dia que passa a questão ambiental tem sido considerada como um fato que precisa ser trabalhada com toda sociedade e principalmente nas escolas, pois as crianças bem informadas sobre os problemas ambientais vão ser adultas mais preocupadas com o meio ambiente, além do que elas vão ser transmissoras dos conhecimentos que obtiveram na escola sobre as questões ambientais em sua casa, família e vizinhos (Medeiros, et al, 2018).

É de extrema importância ensinar a temática ambiental ao aluno, associando a realidade em que está inserido à comunidade escolar, para que o conteúdo abordado não perca o sentido e seja compreendido pelo discente.

Nesse trabalho de pesquisa foi aplicado um questionário com a professora da turma e a coordenadora da escola, contendo 10 questões sobre educação ambiental.

De acordo com as docentes, ambas possuem experiência de mais de cinco anos na educação infantil e trabalham com a educação ambiental em suas aulas.

Segundo as entrevistadas, os motivos que as levam a trabalhar com a educação ambiental são:

"Conscientizar a clientela da importância de se preservar a natureza e dos cui- dados de cada um de nós, na preservação da vida planetária." (Coordenadora da Escola, onde se realizou a pesquisa, 2016).

"Por compreender que quanto mais cedo se começa esse processo formativo/ educativo, maiores serão as possibilidades de a instituição escolar contribuir decisivamente para a formação de uma geração que assumirá a tarefa de cuidar da natureza e dos recursos naturais com autonomia intelectual, iniciativa, criatividade e compromisso. A faixa etária da turma e o espaço físico da escola também são elementos considerados como importantes no trabalho realizado." (Professora da turma, onde se realizou a pesquisa, 2016).

Ambas responderam que não participaram de nenhum curso de formação em Educação Ambiental. A professora da turma relatou que tem interesse em participar quando ocorrem esses cursos de formação, entretanto com sua carga horária de ensino, acaba não tendo possibilidades de participação, visto que normalmente ocorrem durante a semana.

Para uma educação ambiental efetiva multidisciplinar e interdisciplinar a uma necessidade de investir na formação permanente de professores, na qual proporcione aos mesmos conhecimentos relevantes que possam subsidiá-los em suas práticas diariamente. Possibilitando assim que os professores estejam preparados para aprofundar discussões de educação ambiental do ponto de vista de sua disciplina (Aresi e Manica, 2018).

Os professores da educação infantil, na maioria das vezes, não possuem orientação nem material para este trabalho. A temática ambiental dificilmente está presente nos cursos de formação de professores de educação infantil. Os cursos de formação continuada, geralmente são destinados aos professores de Ensino Fundamental e Médio, bem como os materiais produzidos e disponibilizados. A escola e os professores de educação infantil não possuem recursos financeiros para a aquisição de livros e, ao mesmo tempo, possuem dificuldades técnicas para a produção de seus próprios materiais (Hansen, 2017).

Quando questionadas sobre projeto da escola, voltado para a Educação Ambiental e o seu objetivo, a coordenadora relatou que: "é importante esclarecer, informar e conscientizar os alunos com relação à natureza, fonte fundamental de vida para o nosso planeta." Já a professora tem 
um projeto chamado "Outono, tempo de plantar", que tem por objetivo geral: Desenvolver habilidades de observação e compreensão da relação entre a vida dos seres vivos e os elementos existentes na natureza - terra, água, calor do sol, visando à formação de seres humanos comprometidos com os cuidados com o meio ambiente do nosso planeta.

No trabalho de Hansen, (2017) também foi questionado se a escola possuía algum projeto voltado para a educação ambiental. Segundo as professoras, existe na escola, uma parceria firmada com uma empresa que desenvolve projetos de sustentabilidade, visando incorporar diversas ações na escola que servem de apoio ao seu sistema de ensino para aprimorar sua educação ambiental. O principal objetivo desta parceria é transformar a educação ambiental que é empregada hoje nas instituições de ensino, onde somente são realizados trabalhos em hortas, separação de lixo e visitação a zoológicos.

É necessário que além de conceitos e teorias, a escola trabalhe com a formação de valores e de ações práticas para que os alunos possam respeitar e praticar atitudes voltadas à conservação e preservação ambiental.

O professor tem como papel principal, ser o mediador entre a criança e o objeto do seu conhecimento. A ele cabe a tarefa de lançar a pergunta à qual a criança ainda não foi exposta; instigar sua curiosidade das mais diferentes maneiras; definir uma ação pedagógica que vá ao encontro de seu desenvolvimento e sua intenção (Moreira e Costa, 2017).

Em relação às dificuldades encontradas em trabalhar a educação ambiental com as crianças foi relatado que:

“As crianças não dão nenhum trabalho, se estas receberem informações sobre a importância da contribuição de cada uma no processo de preservação do meio ambiente". (Coordenadora, onde se realizou a pesquisa, 2016).

"Dentre as maiores dificuldades estão: insumos, equipamentos, delimitação e preparo do espaço físico para realização de plantios, carência de recurso humano no apoio efetivo a realização das atividades práticas com as crianças." (Professora da turma, onde se realizou a pesquisa, 2016).

No trabalho realizado por Moreira e Costa, (2017) segundo as suas entrevistadas, não há dificulda- des em trabalhar Educação Ambiental com os alunos, visto que eles chegam à escola sabendo dos prejuízos do meio ambiente. Sempre e cada vez mais, as crianças são informadas diariamente sobre este assunto, na televisão, através de programas educativos e até desenho animados, por filmes de DVD, por propagandas e pelas conversas que ouvem dos adultos.

Quando questionadas se as crianças mudam ou adquirem o hábito de preservação ambiental e como é avaliada essa aprendizagem, as respostas foram:
"As crianças mudam ou adquirem o há- bito da preservação ambiental, e são ava- liadas sistematicamente, no cotidiano es- colar." (Coordenadora, onde se realizou a pesquisa, 2016).
"Às vezes, as crianças se tornam guar- diãs de mudas plantadas, dos pés de mi- lhos e pés de feijões. Traduzem as suas aprendizagens na oralidade e transmitem as experiências para as famílias. Mães costumam relatar às "narrativas" das crianças sobre o que aprendem na esco- la." (Professora da turma, onde se reali- zou a pesquisa, 2016).

É importante destacar que a aquisição desses hábitos ocorre de maneiras diferentes para cada criança, por conta disso, esse é um trabalho que deve ser feito diariamente e de forma contínua, para que essa aprendizagem seja gradativa.

Em relação ao processo de separação do lixo produzido pela comunidade escolar e o destino desse resíduo, ambas as entrevistadas responderam que na escola não existe a coleta seletiva do lixo.

Embora ainda não ocorra a coleta seletiva do lixo na escola, em uma conversa informal a coordenadora afirmou que já existem projetos no sentido de obter uma parceria com alguma instituição de reciclagem do lixo. É preciso levar em consideração que em algumas ocasiões, o lixo orgânico produzido da sobra da alimentação na merenda escolar, é reutilizado para a compostagem do solo da escola.

Quando questionadas quais as atividades são realizadas com os alunos fora da escola, objetivando trabalhar a realidade local, sobre o meio ambiente e de que forma são realizadas foi relatado que:

"Não são realizadas atividades com os alunos fora da escola." (Coordenadora, onde se realizou a pesquisa, 2016).

"Ocorre o plantio de mudas nos cantei- 
ros da praça em frente à escola." (Professora da turma, onde se realizou a pesquisa, 2016).

É importante que a escola aproveite melhor os espaços em que está inserida, pois, dessa forma, poderá ocorrer uma reflexão sobre as práticas educativas aprendidas no ambiente escolar pelos educandos, sendo uma maneira de reforçá-las.

Praticar educação ambiental necessita de uma visão ampla do educador, buscando nos pequenos enlaces do cotidiano do aluno, o que pode ser trabalhado trazendo a temática para a realidade do mesmo. (D’artgnan, Neves e Santos, 2017).

No que se refere aos procedimentos pedagógicos mais utilizados para abordar a Educação Ambiental com os educandos, obteve-se como respostas:

"A utilização do próprio contexto escolar, que tendo em vista, a riqueza do espaço torna-se facilitador para nós, tanto a abordagem como a exploração da temática, tais como: Plantação de árvores, feijão, milho, etc. seguidos de cuidados e observações diárias." (Coordenadora, onde se realizou a pesquisa, 2016).

“Área livre da escola; destino do lixo produzido na hora do recreio; Plantio de mudas de árvores dentro e fora da escola; Contato com textos literário que abordem a temática; músicas que tratem de natureza e animais." (Professora da turma, onde se realizou a pesquisa, 2016).

As metodologias utilizadas na educação ambiental são decisivas na construção do conhecimento dos alunos, sendo assim essas metodologias devem ser criteriosamente selecionadas proporcionando ao aluno o conhecimento teórico e permitir que o mesmo tenha contado direto com a natureza possibilitando vivências significativas a partir dos sentidos básicos de percepção humana (Aresi e Manica, 2018).

Essas vivências possibilitam as crianças o sentimento da necessidade de cuidar do meio ambiente. E não basta que a criança aprenda a importância de preservar o meio ambiente, é necessário que ela tome como exemplo, as atitudes dos adultos de seu convívio como educadores e familiares (Hansen, 2017).

As crianças, nessa idade, estão em pleno desenvolvimento de suas capacidades. Devemos assegurar e estimular esse desenvolvimento e é fundamental que, também sejam trabalhados, na escola, valores que são tidos como positivos pela sociedade. Ainda é importante destacar que as escolas de Educação Infantil devem assegurar que todos os direitos da criança estabelecidos pelo Estatuto da Criança e do Adolescente sejam respeitados, sendo que o cuidar e o educar devem sempre andar juntos, mas nunca esquecendo que é nessa fase da vida onde os valores e atitudes que são transmitidos serão levados e refletirão por toda a vida (Schunemann e Rosa, 2017).

De acordo com as respostas obtidas através do questionário, foi possível observar que a educação ambiental é trabalhada diariamente de diferentes maneiras, sendo considerado um processo permanente de desenvolvimento dos educandos, no qual estes acabam por adquirir conhecimentos e experiências para se tornarem aptos no processo de conservação e preservação do meio ambiente.

\section{Considerações finais}

O processo de ensino aprendizagem com práticas em Educação Ambiental foi observado por meio de pequenos atos, sendo o início de grandes transformações, pois os educandos percebem a importância de hábitos e atitudes para conscientização e preservação do meio ambiente.

Através da análise dos questionários e da observação das aulas, foi possível verificar que com a participação da equipe diretiva e técnica da escola, existe um trabalho de Educação Ambiental, pois, todos se envolvem com essa temática no ambiente escolar.

Com relação aos discentes percebeu-se que eles são capazes de aprender sobre o meio ambiente, multiplicando seus conhecimentos, visto que as crianças possuem mais facilidade em criar ou mudar atitudes e são frutos do que eles vivenciam. Os princípios da educação ambiental, precisa ser cada vez mais praticado e visível, para que os educandos desenvolvam ações dentro e fora da escola, através dos valores que adquiriram com o desenvolvimento do trabalho.

Constatou-se que a professora da turma cria momentos para que os alunos exponham seus conhecimentos verificados diariamente com o convívio familiar. Foi desenvolvida a curiosidade e observação das crianças nas atividades propostas. Em relação aos estudantes percebeu-se que eles gostam das aulas práticas, tendo uma participação ativa em todas as etapas do aprendizado. 
Com base nos levantamentos resultantes da presente pesquisa, foi possível averiguar, no que se refere ao ato de plantar na escola, que se faz necessário a utilização de placas de identificação nas espécies de plantas existentes no ambiente escolar, levando em consideração que muitas vezes os alunos não sabem identificá-las. Também se faz de grande importância a retirada do mato com frequência, pois com ele fica difícil distinguir, pelos discentes, as espécies vegetais existentes no ambiente escolar.

Conclui-se que a educação ambiental é discutida diariamente de diferentes formas no ensino infantil e que os alunos observados nessa pesquisa demonstraram curiosidade e interesse pelos temas abordados sobre o meio ambiente. Os educadores abordados no presente trabalho têm consciência da importância de trabalhar a temática ambiental em sala de aula, desde os primeiros níveis de escolarização, devendo ser considerada um processo permanente no desenvolvimento dos estudantes, para que estes adquiram conhecimentos e habilidades, tornando-os conscientes e sensíveis no cuidado com o meio ambiente.

\section{Referências bibliográficas}

ARESI, Daniela; MANICA, Kalina. Educação Ambiental nas escolas públicas: realidade e desafios. 2010. 63f. Pesquisa de Iniciação Científica Universidade comunitária da Região de Chapecó - UNOCHAPECÓ curso de ciências biológicas. Chapecó - SC. 2010. Disponível em: http://docplayer.com.br/10752053-Educacao-ambiental-nas-escolas-publicas-realidade-e-desafios.html. Acesso em: 15/04/2018.

COSTA PINTO, Augusto Coimbra; SILVA, Roseane Nascimento da; COSTA PINTO, Rosilene Coimbra, OLIVEIRA, Francisco Kelsen de; OLIVEIRA, Orlando Silva de. Jogos educativos como ferramenta didática e facilitadora na aprendizagem do aluno em sala de aula. Disponível em: http://propi.ifto.edu.br/ocs/index.php/connepi/vii/paper/viewFile/4484/983. Acesso em: 14/05/2016.

COUTO, Eleni P.; SENA, Marta Ribeiro.; LIMA, Edvânia. EDUCAÇÃO AMBIENTAL NA ESCOLA: Projeto de Pesquisa. Disponível em: http://edumeioambienteirece.blogspot.com. br/2012/10/normal-0-21-false-false-false-pt-br-x_20.html. Acesso em: 21/02/2016.

D'ARTAGNAN, Ítalo; NEVES, Darlan da Conceição; SANTOS, Tassiana de Oliveira. Educação ambiental na educação infantil. Disponível em: http://nead.uesc.br/jornaped2013/anais_2013/ meio ambiente/educacao ambiental na educacao_infantil.pdf. Acesso em: 14/10/2017.

HANSEN, Karem Susan. METODOLOGIAS DE ENSINO DA EDUCAÇÃO AMBIENTAL NO ÂMBITO DA EDUCAÇÃO INFANTIL. Disponível em: http://www.revistaea.org/artigo. php?idartigo=1467. Acesso em: 14/10/2017.

LIMA, Alyne Gessick Pinheiro da Silva; MACEDO, Cicera Camila Alves; SANTOS, Mairla de Olivera; DUMONT, Mariana Macário; DUARTE, Larisse Daiane; CALLOU, Cieusa Maria. EDUCAÇÃO AMBIENTAL: Priorizando o ensino infantil. Disponível em: http://propi.ifto.edu.br/ocs/index.php/connepi/vii/paper/ view/967/2145. Acesso em: 18/10/2017.

LOPES, Sabrina Borges Alcântara; REGO, João Ricardo Souza do; ROSÁRIO, Alessandro Silva do. Educação ambiental como perspectiva de desenvolvimento sustentável para o município Belém, Pará, Brasil. Disponível em: http://www. revistaea.org/artigo.php?idartigo $=3011$. Acesso em: 15/04/2018.

MEDEIROS, Aurélia Barbosa; MENDONÇA, Maria José da Silva Lemes; SOUSA, Gláucia Lourenço de; OLIVEIRA, Itamar Pereira de. A importância da educação ambiental na escola nas séries iniciais. Disponível em: http://www.terrabrasilis.org.br/ecotecadigital/pdf/a-importancia-da-educacao-ambiental-na-escola-nas-series-iniciais.pdf. Acesso em: 16/04/2018.

MOREIRA, Mariana de Castro; COSTA, Leonardo Silva da. A educação ambiental no contexto da educação infantil. Disponível em: http://www. avm.edu.br/docpdf/monografias_publicadas/posdistancia/41217.pdf. Acesso em: 18/10/2017.

OLIVEIRA; Gabriele Caroline dos Santos de.; TONIOSSO, Jose Pedro. EDUCAÇÃO AMBIENTAL: Práticas pedagógicas na educação infantil. Disponível em: http://unifafibe.com. br/revistasonline/arquivos/cadernodeeducacao/ sumario/31/04042014073822.pdf. Acesso em: $02 / 04 / 2016$

SCHUNEMANN, Daniela da Rosa; ROSA, Marcelo Barcellos da. Conscientização ambiental na educação infantil. Disponível em: https://www.google.com.br/ url? $\mathrm{sa}=\mathrm{t} \& \mathrm{rct}=\mathrm{j} \& \mathrm{q}=\& \mathrm{esrc}=\mathrm{s} \& \mathrm{source}=\mathrm{we}-$ $\mathrm{b} \& \mathrm{~cd}=1 \& \mathrm{cad}=\mathrm{rja} \& u a c t=8 \& \mathrm{ved}=0 \mathrm{ahUKEw}-$ j2 kIvIq_vWAhUKj5 A KHbheDaoQFggmMAA\&url=https $\% 3 \mathrm{~A} \% 2 \mathrm{~F} \% 2 \mathrm{Fperiodicos}$. 
ufsm.br\%2Fremoa $\% 2$ Farticle $\% 2$ Fdownload $\%$ 2F2295\%2F1393\&usg=AOvVaw1olz1udttx1SpZO6mAX-87. Acesso em: 18/10/2017.

SILVA, Edriana Gomes da; SANTOS, Simone Lopes dos; CAMPOS, Arnaldo Gonçalves de; OLIVEIRA, Dayse Iara Ferreira de; ALMEIDA, Laura Isabel Marques Vasconcelos de. JOGOS INTERATIVOS: Uma abordagem metodológica para auxiliar no processo de ensino aprendizagem dos alunos do $6^{\circ}$ e $7^{\circ}$ anos na escola CAMPOS SALES em JUSCIMEIRA/MT. Disponível em: http://periodicos.ufsm.br/index.php/ remoa/article/download/20434/pdf. Acesso em: $14 / 05 / 2016$

SILVA, Marilena Loureiro da. Vários colaboradores. VAMOS CUIDAR DO BRASIL: conceitos e práticas em educação ambiental na escola. Disponível em: http://portal.mec.gov.br/dmdocuments/publicacao3.pdf. Acesso em: 30/05/2016.

\section{Sobre os autores}

Alana Danielly Vasconcelos: Doutoranda em Educação, pelo Ppged UFS.

Verusia Maruiza de Souza Macedo Firmino: Especialista em Educação Ambiental com Ênfase em Espaços Educadores Sustentáveis, pela UFS. 